\title{
100 YeARS On, HOW MANY MORE TO Go? CHALLENGES FACING WOMEN IN LAW IN 2013
}

\author{
Monique van Alphen Fyfe
}

\begin{abstract}
One hundred years on from Harriette Vine's graduation, women in law are still confronted with discrimination in their careers. This article examines perceptions of women in law and women's pessimism regarding their prospects. It suggests that legislative, institutional and individual efforts could generate equality within the legal community. Solidarity and agitation to encourage the participation of women at all levels of the profession can best honour the legacy of women's rights in New Zealand.
\end{abstract}

\section{INTRODUCTION}

In 1913 Harriette Vine graduated from Victoria University, a solitary woman in the masculine field of law. She was by all accounts an exceptional woman, maintaining a successful legal career as well as achieving distinction in other fields. One hundred years on, the demographic of law graduates appears different, yet the upper echelons of the vocation remain dominated by pākehā men; this despite significant social and legal transformation in the intervening period.

This article provides an overview of the contemporary culture and challenges women face upon graduation, and offers appraisals of legislative and other options for addressing these challenges. In doing so, particular reference is made to the community women lawyers can and have formed, the importance of legal frameworks and institutions and the place of individuals in the endeavour for equality.

\section{CONTEMPORARY CHALLENGES FACING WOMEN IN LAW}

A woman law graduate in 2013 will have studied in an environment where the majority of students are women. ${ }^{1}$ When being admitted to the bar, that graduate will be amongst a peer group of

* Co-winner of the 2013 Harriette Vine Essay Competition. BArch (Hons). Many thanks to the Wellington Women Lawyers Association, Victoria University of Wellington Law School and Associate Professor Elisabeth McDonald for facilitating the Harriette Vine Essay Writing Competition. 
whom 60 per cent are women. ${ }^{2}$ So far, then, Vine's is far from similar to contemporary experience. From here, however, statistics on the future of women lawyers are a little more sobering. Women make up 44.8 per cent of lawyers overall, approximately 27.7 per cent of judges and only 19 per cent of partners in law firms. ${ }^{3}$ A perceptive woman graduating today can envisage less than favourable prospects of future promotion.

These issues are not peculiar to law; they permeate professions in many first world regions. Across professions, movement toward equality at senior levels is abnormally slow in light of notably increased participation at university and workplace entry. ${ }^{4}$

New Zealand lags behind other countries in achieving substantive equality, ${ }^{5}$ a disappointing effort from a country that accepts praise for legislation initiating suffrage for women in 1893. New Zealand is proud of this pioneering marker, mythologising not only the political realities of the time, but also the extent of change it symbolised. For example, although some women were enabled to vote in 1893, it was not until many years later that women were able to stand for Parliament. Equal parliamentary representation has yet to be attained.

To apply this theme to law, Ethel Benjamin was the first woman to enter the legal profession in 1897, an admirable achievement ahead of the United Kingdom. ${ }^{6}$ Her experience in practice was less than ideal, including a lack of acceptance by peers and reduced access to resources and clients. ${ }^{7}$ Benjamin eventually left the profession altogether. Vine herself persevered, but never made partner despite dedicated service to one firm over many years.

One hundred years later, despite the benefit of significant numbers of women graduates and anti-discrimination legislation, the career outcomes of both Benjamin and Vine would not be out of place. As the statistics above show, many measures of equality anticipated by early accomplishments are yet to be fulfilled. Some businesses aspire to 10 per cent representation, ${ }^{8}$ and in others the vision for equality is being eroded. New Zealand's 1998 targets of equal representation

1 Human Rights Commission New Zealand Census of Women's Participation 2012 (Human Rights Commission, Wellington, 2012) at 75.

2 At 75.

3 At $74-76$.

4 At 2 .

5 At 3 .

6 Lady Hale "Dignity" (paper presented to the 14th Annual New Zealand Law Foundation Ethel Benjamin Commemorative Address, Dunedin, 7 May 2010) at 1.

7 Sian Elias "Address to the Australian Women Lawyers' Conference" (paper presented to Australian Women Lawyers' Conference, Melbourne, 13 June 2008) at 2.

8 Human Rights Commission, above n 1, at 3. 
on statutory bodies have now been reduced to 45 per cent. ${ }^{9}$ As noted by the Human Rights Commission, such weak targets reveal a "limited faith in the ability of New Zealanders to lead and innovate" and "dampen women's expectations of progress". ${ }^{10}$

Legislation such as the Equal Pay Act 1972 attempted to remove explicitly sexist employment strategies, but the residual and structural sexism that remains is more immune to the patient approach currently adopted to install substantive equality. It is this structural sexism that now hinders women's progress. As a 2014 study of women in law shows, this give rise to a sense of resignation that the status quo is so ingrained as to be insurmountable. ${ }^{11} \mathrm{By}$ its very nature, structural sexism, and its intersections with structural racism, is much more challenging to identify and eliminate.

It is difficult to disagree with the notion that a person promoted to a position should be capable of performing in it; the concept of meritocracy is, on its face, a noble one. Given that a lack of qualified women is no longer an available excuse, it is increasingly difficult to view workplace promotions as a product of a meritocracy when a particular group of qualified people are consistently overlooked. Instead this demands an examination of alternative causes operating unconsciously beneath the surface.

The definition of merit is worthy of consideration. For a lawyer, merit is often associated with masculine attributes, without critical examination of what effect this has on practice. As one woman lawyer noted, a lawyer with merit "is often a classic, stereotypical, loud, confident, articulate ... male person", whereas the traits women often possess that may make them better lawyers "are not perceived as merit". 12

Key to this are cultural gender ideologies that presume inherent traits of men and women, and the impact these have on perceptions of skill in leadership. The underlying assumptions are that men are more inclined to masculine self-promotion, assertiveness and control, whereas women tend towards feminine compassion and nurturing the community. ${ }^{13}$ The former traits are seen as desirable in a traditional understanding of effective leadership, whereas the latter are an impediment to such.

9 At 3 .

10 At 3 .

11 Auckland Women Lawyers' Association Women's career progression in Auckland law firms: Views from the top, views from below 2014 (Gender \& Diversity Research Group, AUT University, Auckland, 2014) at 58.

12 At 64 .

13 AH Eagly and L Carli "Women and the Labyrinth of Leadership" (2007) 85(9) Harv Bus Rev 62 at 66. 
Whilst conforming to masculine leadership styles may appear to be a straightforward solution, the approach is not universally reliable. Studies suggest assertive women who adopt masculine strategies are not perceived as effective leaders. ${ }^{14}$ Women are not only perceived to be less capable of exhibiting qualities of good leaders, but they also achieve less favourable evaluations of their actual leadership ability because "behaviour commonly associated with leadership is perceived as less desirable in women than men". ${ }^{15}$ The unattainable symmetry traversed by professional women is to be at once feminine and agentic. ${ }^{16}$ Contemporary studies on leadership show that the transformative style more commonly employed by women is increasingly considered to be more effective, which may in turn be seen as threatening to existing leaders resistant to changes in the workplace culture. ${ }^{17}$ This error is only compounded when the increasing number of women clients is acknowledged.

In order to counter these structural and cultural setbacks, women often, consciously or unconsciously, undertake considerable effort in their work beyond that required of their male peers. They become "exceptional" women - exceptions to the cultural normative idea of what a woman should be. They may sacrifice family for career, pursue academic enquiry and serve charitable causes. Such exceptionalism is eloquently illustrated by Vine herself with her commitment to ongoing education, considerable success in extracurricular activities and her decision not to have a family of her own. That there are still few women at the pinnacle of the profession illustrates this exceptional requirement is a burden falling far more heavily on women than men.

Another significant and related factor is the preponderance of informal workplace networks that favour men over women for promotion and mentoring. ${ }^{18}$ Whilst the exceptional woman might be accepted into male workplace networks, many women lawyers find themselves without the same level of access to senior staff and the associated benefits. ${ }^{19}$ The framework that disallows women access to networks and mentoring is often the same framework that decides who to hire and promote. Unconscious bias on the part of (likely) male decision-makers often reinforces the lack of gender diversity through a simple lack of analysis of operating definitions of merit and leadership.

14 Janice D Yoder "Making Leadership Work More Effectively for Women" (2001) 57 Journal of Social Issues 815 at 818 .

15 Susan Glazebrook "Looking Through the Glass: Gender Inequality at the Senior Levels of New Zealand's Legal Profession" (paper presented to Chapman Tripp - Women in Law, Wellington, September 2010).

16 Laurie A Rudman and Peter Glick "Prescriptive Gender Stereotypes and Backlash Toward Agentic Women" (2001) 57 Journal of Social Issues 743 at 759.

17 Alice H Eagly and Mary C Johannesen-Schmidt "The Leadership Styles of Women and Men" (2001) 57 Journal of Social Issues 781 at 793 and 795.

18 Eagly and Carli, above n 13, at 66.

19 Auckland Women Lawyers' Association, above n 11, at 51-53. 
In the legal profession, demands on time can be extreme and at odds with the social demands on women. Women face the conflict of conforming to traditional masculine work ethics whilst maintaining family and community relationships, and doing more than their share of domestic work $;{ }^{20}$ a conflict that is sometimes negotiated to the detriment of personal relationships. ${ }^{21}$ A lack of enthusiasm for flexible working hours from partners, ${ }^{22}$ and the perception of employees that making use of such flexibility will harm promotion prospects, ${ }^{23}$ only compounds this problem. It is one of many that women face to a greater extent than men in the pursuit of their career.

\section{WHY AND WHAT TO CHANGE}

It is not a controversial view that a legal community and judiciary that better reflects the diversity of the community it serves is inherently desirable. Such diversity lends legitimacy to and better ensures relevancy of the law profession and judicial decisions.

The presence of women lawyers and judges, along with members of other marginalised groups, is essential in this endeavour to break down traditional stereotypes and to rebuild the profession with foundations of equality. Writing in an extrajudicial capacity, Elias CJ notes women (and by extension minorities) offer perspectives that can shape legal work to suit shifts in the modern environment and reflect society's values in legal decisions. ${ }^{24}$ Commenting on the judiciary, she considers the presence of those other than pākehā men are more likely to notice unconscious bias in claimed objectivity and have "already unsettled many of the assumptions that used to perpetuate inequality". ${ }^{25}$ Also writing extra-judicially, Glazebrook $\mathbf{J}$ states "it is not only women but society as a whole that has an immense amount to gain from the promotion of female participation in the workforce". ${ }^{26}$

The presence of women in senior roles creates role models and mentors for those following in their footsteps. Whilst it is true that the concept of "peer deprivation" has been lessened with

20 At 35; Sheree J Gibb, David M Fergusson and Joseph M Boden "Gender Differences in Paid and Unpaid Work: findings from a New Zealand birth cohort" (2013) 9 Policy Quarterly 65 at 67.

21 Susan Glazebrook "Gender Equality in the Workforce: A Work In Progress" (paper presented to the Annual Professional Women's Dinner, Christchurch, 22 October 2009) at 10.

22 New Zealand Law Society Women's Consultative Group Women Lawyers' Survey (2005).

23 Auckland Women Lawyers' Association, above n 11, at 13.

24 Sian Elias "Justice for One Half of the Human Race? Responding to Mary Wollstonecraft's Challenge" (paper presented to Canadian Chapter of the International Association of Women Judges' Conference, Vancouver, 10 May 2011) at 7; Sian Elias "Changing our World" (paper presented to International Association of Women Judges' Conference, Sydney, 4 May 2006) at 8.

25 Elias "Changing our World", above n 24, at 9-10.

26 Glazebrook, above n 21, at 12. 
increased participation by women in the field, ${ }^{27}$ the capacity of the few women in senior positions to effectively mentor the large numbers below them is strained.

Although many women gain positively from working through these problems individually, relying on individuals alone to compensate for structural inequalities is inherently unfair and ultimately ineffective. Recent research indicates women perceive limited prospects of personal success where, despite individual desire for change, there is little in the way of visible agitation. ${ }^{28}$ Women in law can benefit from a range of supportive opportunities such as legal intervention, organised communities, mentoring and allies in the field.

A potentially seismic shift may be needed in workplace culture to dislodge the remaining components of structural sexism. Acceptance of different and potentially more effective styles of leadership, instigation of flexible work hours, and transparency and diversity in promotion are laudable strategies for the end goal of substantive equality.

But perhaps the seismic shift is required beyond the scope of just the legal profession. The legacy of the suffragettes, and of Vine, is one to be honoured not simply by seeing privileged women accepted into senior law positions while ignoring women in the wider community, but by ensuring that change comes to all women and all minorities: ${ }^{29}$

For [the suffragettes], the vote was not the end, but the beginning. There was no point in gaining the vote if women were not to change the world. The suffragettes aimed to make the world a better place, through practical gains for real people in our communities.

\section{HOW TO EFFECT CHANGE}

The Chief Justice has lamented that women have previously "bought into the lie that the advancement of women in the legal profession was just a matter of time and numbers. And that merit would out." ${ }^{30}$ Without doubt change is needed. Indeed, it is overdue. Reliance on minimal legal intervention in the hope that society would take heed and fulfil the substantive goal was courageous and trusting, but sadly misguided. Embracing substantive change through both legal and other means can provide a holistic approach that has the moral and legal clout to succeed.

As the Human Rights Commission discussed, a non-exhaustive list of actionable options includes: discuss, debate, yell, speak, fight, vote, demand and change. ${ }^{31}$ Distilled, the list might read: legislate, organise, communicate and identify.

27 Elias "Justice for One Half of the Human Race?", above n 24, at 1.

28 Auckland Women Lawyers' Association, above n 11, at 58.

29 Elias, above $\mathrm{n} 7$, at 7.

30 Elias, above n 7, at 6.

31 Human Rights Commission, above n 1, at 4. 
New Zealand society is somewhat reticent in recent times to use interventionist statute law to cover substantive equality issues. Attempts such as the Equal Pay Act 1972 have not resolved the issue as conclusively as hoped, but this is not a reason to abandon legal methods entirely. As illustrated by the recent Employment Court decision regarding structural pay discrimination in women dominated professions, legal methods are certainly not without their place. ${ }^{32}$

It is perhaps unpleasant to contemplate forcing wholesale culture change within a profession and, by in large, the limited intervention approach has succeeded in getting substantial numbers of women practicing law. It has failed, however, to further their interests beyond entry into the profession. Women within the profession want change, but the lack of publicised strategies leaves many without positive expectation. The need for a formalised system to reignite progress towards equality within the profession is clearly demonstrated.

Temporary measures to alleviate discrimination are anticipated by the Human Rights Act 1993. ${ }^{33}$ Despite this, there is particular reluctance to make provision for mandatory quotas for women's representation in both private and public institutions, due in part to a fear that this would lead to promotions without merit. The two-step approach, where a candidate must first meet a certain level of merit, allays this concern and is favoured by the United Kingdom in judicial appointments. ${ }^{34}$ Although there is some question as to whether this approach has greatly improved the proportion of women judges, it is one tactic of many to be employed.

The legal community is furnished with parallel institutions of private firms and the judiciary. Forcing change in private business in a western liberal democracy may be difficult and politically unpalatable. The close proximity of a public body such as the judiciary, however, lends itself to being an exemplar to the private sector. When reviewing the Judicature Act 1908, the Law Commission recommended a simple amendment to the appointment process to give regard to the desirability of the judiciary reflecting gender, cultural and ethnic diversity. ${ }^{35}$ Adapting the judiciary to diverse representation establishes a considerable coercive power to encourage change in related communities.

The legal profession is built on centuries of history as a male only workplace culture. There is no denying that the profession is still heavily geared towards a male perspective and experience of the world. Women lawyers are working within a system that has centuries of development as

32 Service and Food Workers Union Nga Ringa Tota Inc v Terranova Homes and Care Limited [2013] NZ Emp C 157.

33 Section 73.

34 Ministry of Justice (UK) Appointments and Diversity 'A Judiciary for the 21st Century': Response to public consultation (11 May 2012) at [96]. Constitutional Reform Act 2005 (UK), s 64.

35 Law Commission Review of the Judicature Act 1908: Towards a New Courts Act (NZLC R126, 2012) at 55. 
"male"; the "old boys" network is still felt by many young women. ${ }^{36}$ Women have the unenviable task of forging pathways, communities and traditions within the current institution and in a much shorter time than has been afforded to men. To create a sophisticated community in a comparatively short time requires directed effort and formal systems. To this end, women have created associations, and networking and mentoring groups to provide support to ensure individual women feel part of a larger community. Publications and research, such as that recently commissioned by the Auckland Women Lawyers' Association, promote awareness of the issues faced and the networks available for support.

Individual contributions to the community are critical to its success. Contributions can scale from a thoughtful appraisal of another woman's work, to concepts of paying forward though mentoring, advocating for change and simply being stoically determined, as our foremothers such as Vine were, in challenging times.

History suggests that legislative change follows agitation from dedicated groups. Significant, albeit slow, social change ensues. Momentum is currently restrained; vocal declarations of discontent are needed for legal change to effect cultural shifts in workplace equality. Agitation and solidarity, whether loud, blunt or subtle, but always unequivocal and unwavering, is necessary to engender just and crucial change that has been promised for some time but taken far too long.

\section{100 YEARS FROM NOW}

The challenges facing women lawyers in 1913 and 2013 are starkly different at first blush. Those of 100 years ago appear blatant to our liberated eye operating in hindsight. Those of 2013 are almost too subtle to identify, but quantitative and qualitative research demonstrates structural inequality prevalent within the legal profession. It does bear contemplation what a woman 100 years from now, particularly one of non-pākehā decent, might have to say regarding the obviousness of our contemporary challenges.

Whilst historical and contemporary challenges manifest themselves in slightly different ways, they are built on much the same notions: traditionally feminine qualities are inferior to, and incompatible with, the masculine sphere of the legal profession. This structural discrimination is pervasive; without addressing it, inequality will remain. Maintaining complacency in the face of demonstrable injustice is becoming an increasingly unsupportable position. If we believe, as our predecessors did, in the justness of this cause, and the inherent right for women to be accepted and welcomed at all levels of the profession, we owe it to ourselves and our fellow women to stand unequivocally for equality.

36 Auckland Women Lawyers' Association, above n 11, at 8 and 36. 